\section{Proteome-wide Analysis and CXCL4 as a Biomarker in Systemic Sclerosis}

\author{
L. van Bon, A.J. Affandi, J. Broen, R.B. Christmann, R.J. Marijnissen, L. Stawski, \\ G.A. Farina, G. Stifano, A.L. Mathes, M. Cossu, M. York, C. Collins, M. Wenink, \\ R. Huijbens, R. Hesselstrand, T. Saxne, M. DiMarzio, D. Wuttge, S.K. Agarwal, \\ J.D. Reveille, S. Assassi, M. Mayes, Y. Deng, J.P.H. Drenth, J. de Graaf, \\ M. den Heijer, C.G.M. Kallenberg, M. Bijl, A. Loof, W.B. van den Berg, \\ L.A.B. Joosten, V. Smith, F. de Keyser, R. Scorza, C. Lunardi, P.L.C.M. van Riel, \\ M. Vonk, W. van Heerde, S. Meller, B. Homey, L. Beretta, M. Roest, \\ M. Trojanowska, R. Lafyatis, and T.R.D.J. Radstake
}

\section{A BSTRACT}

\section{BACKGROUND}

Plasmacytoid dendritic cells have been implicated in the pathogenesis of systemic sclerosis through mechanisms beyond the previously suggested production of type I interferon.

\section{METHODS}

We isolated plasmacytoid dendritic cells from healthy persons and from patients with systemic sclerosis who had distinct clinical phenotypes. We then performed proteome-wide analysis and validated these observations in five large cohorts of patients with systemic sclerosis. Next, we compared the results with those in patients with systemic lupus erythematosus, ankylosing spondylitis, and hepatic fibrosis. We correlated plasma levels of CXCL4 protein with features of systemic sclerosis and studied the direct effects of CXCL4 in vitro and in vivo.

\section{RESULTS}

Proteome-wide analysis and validation showed that CXCL4 is the predominant protein secreted by plasmacytoid dendritic cells in systemic sclerosis, both in circulation and in skin. The mean $( \pm$ SD) level of CXCL4 in patients with systemic sclerosis was $25,624 \pm 2652$ pg per milliliter, which was significantly higher than the level in controls (92.5 \pm 77.9 pg per milliliter) and than the level in patients with systemic lupus erythematosus (1346 \pm 1011 pg per milliliter), ankylosing spondylitis (1368 \pm 1162 pg per milliliter), or liver fibrosis (1668 \pm 1263 pg per milliliter). CXCL4 levels correlated with skin and lung fibrosis and with pulmonary arterial hypertension. Among chemokines, only CXCL4 predicted the risk and progression of systemic sclerosis. In vitro, CXCL4 downregulated expression of transcription factor FLI1, induced markers of endothelial-cell activation, and potentiated responses of toll-like receptors. In vivo, CXCL4 induced the influx of inflammatory cells and skin transcriptome changes, as in systemic sclerosis.

\section{CONCLUSIONS}

Levels of CXCL4 were elevated in patients with systemic sclerosis and correlated with the presence and progression of complications, such as lung fibrosis and pulmonary arterial hypertension. (Funded by the Dutch Arthritis Association and others.)
The authors' full names, degrees, and affiliations are listed in the Appendix. Address reprint requests to Dr. Radstake at the Department of Rheumatology and Clinical Immunology, Laboratory of Translational Immunology, University Medical Center Utrecht, Heidelberglaan 100, 3584 CX Utrecht, the Netherlands, or at t.r.d.j.radstake@umcutrecht.nl.

Drs. van Bon, Affandi, Broen, Lafyatis, and Radstake contributed equally to this article.

This article was published on December 18, 2013, at NEJM.org.

N EnglJ Med 2014;370:433-43. DOI: 10.1056/NEJMoal114576 Copyright (c) 2013 Massachusetts Medical Society. 
YSTEMIC SCLEROSIS (ALSO CALLED SCLEROderma) is a complex heterogeneous fibrosing autoimmune disorder with an unknown pathogenesis. The way in which its three major pathologic hallmarks - extensive fibrosis, vasculopathy, and immune dysfunction - are interconnected is unknown. Mechanistic understanding is limited, in part, by a lack of animal models and by clinically heterogeneous patient populations. ${ }^{1}$ This disorder is classified into two major subtypes on the basis of the extent of cutaneous fibrosis: limited cutaneous and diffuse cutaneous systemic sclerosis. ${ }^{2}$ Pulmonary fibrosis and pulmonary arterial hypertension are the two most serious complications - currently the major causes of death among patients with this disorder. Thus, in addition to clarifying pathogenic mechanisms, the identification of biomarkers for the presence and progression of clinical complications of systemic sclerosis has potential use in the assessment of disease activity.

On the basis of key observations by LeRoy ${ }^{3}$ that collagen production was increased in fibroblasts that were isolated from scleroderma skin and cultured in vitro, much of the research on systemic sclerosis has focused on altered fibroblast biology. More recent studies, however, indicate that immune cells are important in pathogenesis.4,5 Indeed, genetic association studies have revealed that the most highly associated susceptibility markers include the genes encoding immune signaling molecules T-bet, ${ }^{6}$ STAT4, 7,8 and IRF5,9 and the T-cell-receptor zeta chain. ${ }^{8}$ STAT4 and IRF5 are both implicated in the secretion of type I interferon, a cytokine that has been shown to be present in both cutaneous and peripheral-blood mononuclear cells. ${ }^{10}$ Plasmacytoid dendritic cells are the major source of type I interferon, and as such have been implicated in multiple autoimmune conditions that have a type I interferon signature, including systemic lupus erythematosus, ${ }^{11}$ Sjögren's syndrome, ${ }^{12}$ and rheumatoid arthritis. ${ }^{13}$ Although two studies have shown that serum samples obtained from patients with systemic sclerosis showed type I interferoninducing activity, the role of plasmacytoid dendritic cells in systemic sclerosis has not been fully explored. ${ }^{14,15}$ The aim of our study was to identify a possible role for plasmacytoid dendritic cells in the pathogenesis of systemic sclerosis that is associated with the clinical phenotype.
METHODS

\section{STUDY PATIENTS}

In our study, we evaluated 779 patients with systemic sclerosis - 462 with the limited cutaneous subtype (limited disease) and 317 with the diffuse cutaneous subtype (diffuse disease). Throughout the study, the patient cohort from the Boston University School of Medicine was the identification cohort for studies of plasmacytoid dendritic cells and included 20 healthy donors and 53 patients with systemic sclerosis; the latter included 16 patients with limited disease, 18 with late diffuse disease (duration, $>3$ years), and 19 with early diffuse disease (duration, <2 years). In addition, for the chemokine analysis, plasma was obtained from an additional 22 healthy donors, 15 patients with limited disease, and 31 patients with diffuse disease. The replication cohorts comprised patients from the University of Nijmegen, the Netherlands (148 patients), Lund, Sweden (197), Milan (120), Verona, Italy (18), Ghent, Belgium (79), and Houston (50). Samples from an additional 68 patients from Milan were included to compare CXCL4 levels in patients with early systemic sclerosis with levels in patients in various phases of preclinical systemic sclerosis, including those with only Raynaud's phenomenon with or without specific antinuclear antibodies, anti-topoisomerase or anti-centromere antibodies, or capillary nailfold lesions resembling systemic sclerosis.

For the studies of the CXCL4 expression in plasmacytoid dendritic cells, skin sections were obtained from 3 patients with early diffuse systemic sclerosis from Boston University and 6 patients with late diffuse disease from the University of Dusseldorf, Germany. All patients met the preliminary criteria of the American College of Rheumatology for the classification of systemic sclerosis (Table 1). ${ }^{16}$ The clinical phenotype of the patients is described further in the Supplementary Appendix, available with the full text of this article at NEJM.org. All samples were obtained after patients provided written informed consent and after approval of the study by the institutional review board at each participating center.

To compare CXCL4 levels in samples obtained from patients with systemic sclerosis with levels in samples from healthy donors, we obtained plasma samples from 257 age- and sex-matched healthy persons from the Nijmegen Biomedical 
Study. ${ }^{17}$ To compare CXCL4 levels in patients with systemic sclerosis with levels in patients with other clinical conditions, we determined the levels of CXCL4 in stored samples from 109 patients with systemic lupus erythematosus who fulfilled the American College of Rheumatology criteria ${ }^{18,19}$ (Table S1 in the Supplementary Appendix), from 93 patients with ankylosing spondylitis ${ }^{20}$ (Table S2 in the Supplementary Appendix), and from patients with various stages of liver fibrosis (see the Supplementary Appendix for details).

\section{CELL-BASED STUDIES AND MEASUREMENT OF INFLAM MATORY MEDIATORS}

All the techniques that we used in this study are described in detail in the Supplementary Appendix. Briefly, we performed proteome-wide analysis of supernatant from plasmacytoid dendritic cells, using surface-enhanced laser desorption/ ionization-time-of-flight (SELDI-TOF) mass spectrometry. Quantification of secreted cytokines was performed with the use of an enzyme-linked immunosorbent assay or Luminex immunoassay. We used primary endothelial cells and peripheral plasmacytoid dendritic cells to study the effect of CXCL4 in vitro. To assess CXCL4 function in vivo, C57BL/6 mice were exposed to subcutaneous CXCL4 for further RNA and histologic analysis.

\section{STATISTICAL ANALYSIS}

We used Student's t-test or the Mann-Whitney $\mathrm{U}$ test for the analysis of quantitative traits, as appropriate, and the Kaplan-Meier method to estimate survival in patients with high CXCL4 levels at baseline, as compared with those with low CXCL4 levels, with survival time set at 24 months. After verifying that the proportionality of hazards was not violated, we used Cox regression analysis to estimate the effect size of CXCL4 categorization on the basis of plasma levels on the time to event; results are presented as hazard ratios along with their asymptotic 95\% confidence intervals. Listwise deletion was used in cases with missing data.

To assess the most effective cutoff value for CXCL4, we used DeLong's method to compute a receiver-operating-characteristic (ROC) curve. The area $( \pm$ SE) under the ROC curve was $0.987 \pm 0.009$ (95\% confidence interval [CI], 0.952 to 0.996 ; $\mathrm{P}<0.001)$. At the cutoff value for CXCL4 of 11,589 pg per milliliter, the sensitivity was $100 \%$, and

\begin{tabular}{|c|c|c|}
\hline Characteristic & $\begin{array}{l}\text { Limited Cutaneous } \\
\text { Systemic Sclerosis } \\
\qquad(\mathrm{N}=462)\end{array}$ & $\begin{array}{l}\text { Diffuse Cutaneous } \\
\text { Systemic Sclerosis } \\
\qquad(\mathrm{N}=317)\end{array}$ \\
\hline Female sex — no. (\%) & $378(82)$ & $218(69)$ \\
\hline Age at onset $-y r$ & $42.4 \pm 12.3$ & $43.8 \pm 11.2$ \\
\hline Disease duration $-\mathrm{yr}$ & $9.4 \pm 8.0$ & $5.8 \pm 6.2$ \\
\hline $\begin{array}{c}\text { Positive test for antinuclear } \\
\text { antibodies - \% }\end{array}$ & 97 & 86 \\
\hline $\begin{array}{l}\text { Modified Rodnan skin-thickness } \\
\text { score } †\end{array}$ & $5.4 \pm 2.4$ & $15.9 \pm 8.2$ \\
\hline Pulmonary arterial hypertension — \% & 39 & 23 \\
\hline Lung fibrosis - \% & 26 & 48 \\
\hline \multicolumn{3}{|l|}{ Current therapies — \% } \\
\hline Mycophenolate mofetil & 0 & 41 \\
\hline Cyclophosphamide & 0 & 23 \\
\hline Prednisolone & 25 & 30 \\
\hline Hydroxychloroquine & 18 & 11 \\
\hline Anti-interleukin-3 antibody & 0 & 2 \\
\hline Methotrexate & 1 & 5 \\
\hline Tacrolimus & 12 & 0 \\
\hline
\end{tabular}

* Plus-minus values are means \pm SD.

$\uparrow P=0.03$ for the comparison between patients with diffuse disease and those with limited disease. There were no other significant between-group differences. Scores on the modified Rodnan skin-thickness scale are calculated by clinical palpation of 17 body areas, with the thickening of each area scored as 0 (normal), 1 (mild), 2 (moderate), or 3 (severe).

the specificity was $94 \%$. At the cutoff value of 9789 pg per milliliter, the sensitivity was $100 \%$, and the specificity was $93 \%$. For a practical cutoff for clinical practice, we chose 10 ng per milliliter for CXCL4, to be conservative with respect to sensitivity. P values of less than 0.05 (all two-sided) were considered to indicate statistical significance and were adjusted with the use of a Bonferroni correction.

\section{RESULTS}

CXCL4 SECRETION BY PLASMACYTOID DENDRITIC CELLS

To assess the production of type I interferon by plasmacytoid dendritic cells, we isolated BDCA4+ cells from 20 healthy donors and compared results in their plasmacytoid dendritic cells with those in cells obtained from 54 patients with systemic sclerosis: 17 with limited disease and 37 with diffuse disease (Fig. S1A in the Supplementary Appendix). Patients with diffuse disease 
were further stratified according to disease duration, with 18 patients in the early-disease group and 19 in the late-disease group. A chromogenic reaction was reproducibly present in the media from the plasmacytoid dendritic cells obtained from patients with early systemic sclerosis. Measurement of multiple inflammatory mediators in these supernatants showed almost no detectable production of type I interferon or other mediators, with differential expression of only interleukin-8 and interleukin-6 (Fig. S1B through S1G in the Supplementary Appendix).

Proteome-wide measurements from eight independent experiments robustly showed that only plasmacytoid dendritic cells from patients with early systemic sclerosis secreted a unique pattern of peaks that were identified as CXCL4, CTAP-III, S100A8/9, and lysozyme (Fig. 1A, and Fig. S1H in the Supplementary Appendix). Confirmatory assessments showed markedly increased levels of CXCL4 in patients with systemic sclerosis (Fig. 1B). Increased levels of CXCL4 messenger RNA (mRNA) were observed only in purified plasmacytoid dendritic cells, and increased CXCL4 protein expression was observed in circulating plasmacytoid dendritic cells (Fig. S1I and S1J) and in plasmacytoid dendritic cells in skin from patients with systemic sclerosis (Fig. 1C, and Fig S1K in the Supplementary Appendix).

\section{CXCL4 IN THE CIRCULATION}

In the identification cohort, levels of circulating CXCL4 were markedly higher in patients with systemic sclerosis than in healthy controls and were particularly high in patients with early diffuse disease ( $\mathrm{P}<0.001$ for both comparisons) (Fig. 2A). Increased CXCL4 levels were successfully validated in the replication cohort (which included 86 patients with systemic sclerosis with limited cutaneous disease, 38 with late diffuse disease, and 37 with early diffuse disease) and were compared with 129 age- and sex-matched healthy donors and 109 patients with systemic lupus erythematosus, 93 with ankylosing spondylitis, and 93 with liver fibrosis (Fig. 2B).

In addition, in the replication cohort, there were clear differences between the two groups in previously suggested biomarkers for systemic sclerosis, such as CCL5, ${ }^{21}$ von Willebrand factor, ${ }^{22}$ CCL18, ${ }^{23}$ CCL2, ${ }^{24}$ and CXCL10 ${ }^{24}$ (Fig. S2B in the Supplementary Appendix). In an exploratory analy- sis, we found that CXCL4 levels gradually and significantly increased per group in the following order: patients with primary Raynaud's phenomenon, those with Raynaud's phenomenon and positive antinuclear antibodies, and those with very early systemic sclerosis (Raynaud's phenomenon plus anti-topoisomerase or anti-centromere antibodies and the presence of nailfold angiopathy), whereas the levels of CCL2, CXCL10, CCL5, von Willebrand factor, and CCL18 did not increase (Fig. S2C in the Supplementary Appendix).

We next assessed the association between CXCL4 levels and the clinical phenotype. CXCL4 levels correlated with the extent of skin fibrosis in the limited cutaneous phenotype $\left(\mathrm{R}^{2}=0.59\right.$, $\mathrm{P}<0.001)$ and the diffuse cutaneous phenotype $\left(R^{2}=0.74, P<0.001\right)$. Patients with high levels of circulating CXCL4 ( $\geq 10$ ng per milliliter), as compared with those with low CXCL4 levels, had significantly earlier evidence of lung fibrosis, as measured by a relative decline of more than $30 \%$ in the forced vital capacity (hazard ratio, 3.67; $95 \%$ CI, 2.31 to $4.31 ; \mathrm{P}<0.001$ ) or by the presence of bilateral fibrosis on high-resolution computed tomography (CT) (hazard ratio, 2.60; 95\% CI, 1.61 to 5.26; P<0.001) (Fig. 2C). Furthermore, patients with systemic sclerosis who had evidence of pulmonary arterial hypertension had markedly increased circulating CXCL4 levels, as compared with those without such evidence $(19,078 \pm 629$ vs. $5023 \pm 329$ pg per milliliter, $\mathrm{P}<0.001)$. High CXCL4 levels were associated with the earlier development of pulmonary arterial hypertension, as determined on right-heart catheterization (hazard ratio, 8.33; 95\% CI, 4.43 to 15.72; P<0.001) (Fig. 2D).

We also investigated whether CXCL4 could serve as a biomarker in a prospective cohort of 79 patients who were followed for 18 months. Patients who had a high baseline level of CXCL4, as compared with other biomarkers for systemic sclerosis, had a significantly faster decline in diffusion capacity of the lung for carbon monoxide $(\mathrm{P}=0.002)$, higher prevalence of high-resolution CT-confirmed lung fibrosis $(22 \%$ vs. $8 \%, \mathrm{P}<0.001)$, and faster progression of skin fibrosis $(\mathrm{P}<0.001)$ (Fig. S2D in the Supplementary Appendix). None of the other chemokines that were measured correlated with progression. Table S3 in the Supplementary Appendix provides a summary of CXCL4 plasma levels in all the study cohorts. 


\section{IN VITRO STUDIES}

We examined CXCL4 in vitro using plasma obtained from patients with systemic sclerosis and commercially available CXCL4. Both the CXCL4 and plasma induced the secretion of endothelin 1 and down-regulation of the transcription factor FLI1 in human umbilical-vein endothelial cells (HUVECs) and human dermal microvascular endothelial cells (HDMECs). The addition of anti-CXCL4 antibody attenuated these responses

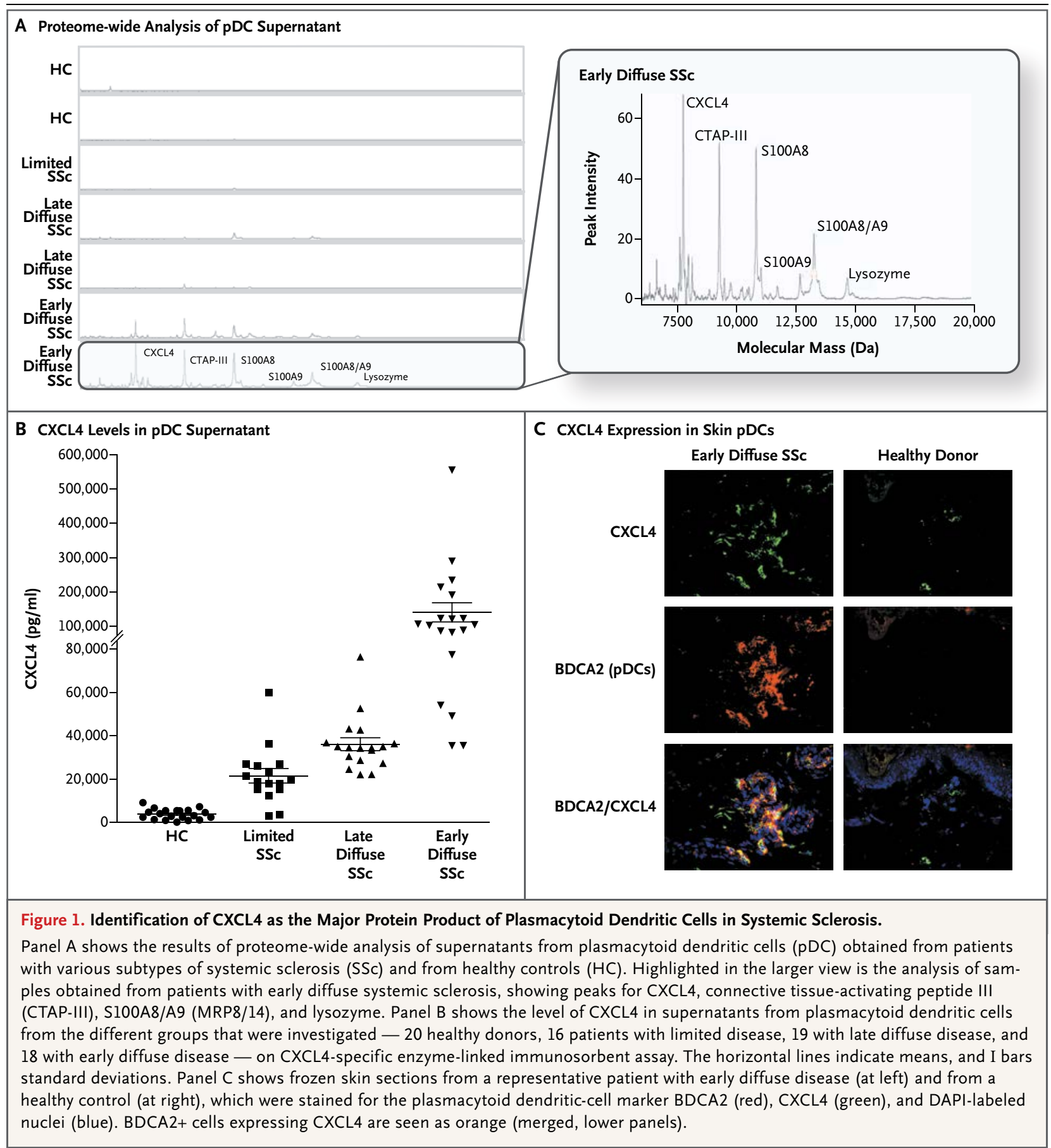


(Fig. $3 \mathrm{~A}$ and 3B). In addition, CXCL4 inhibited the effect of vascular endothelial growth factor on the proliferation of HDMECs $(\mathrm{P}<0.001)$, a finding that we speculate may underlie the rar- efaction of vessels in patients with systemic sclerosis (data not shown).

Plasmacytoid dendritic cells and their activation by toll-like receptors are thought to play a

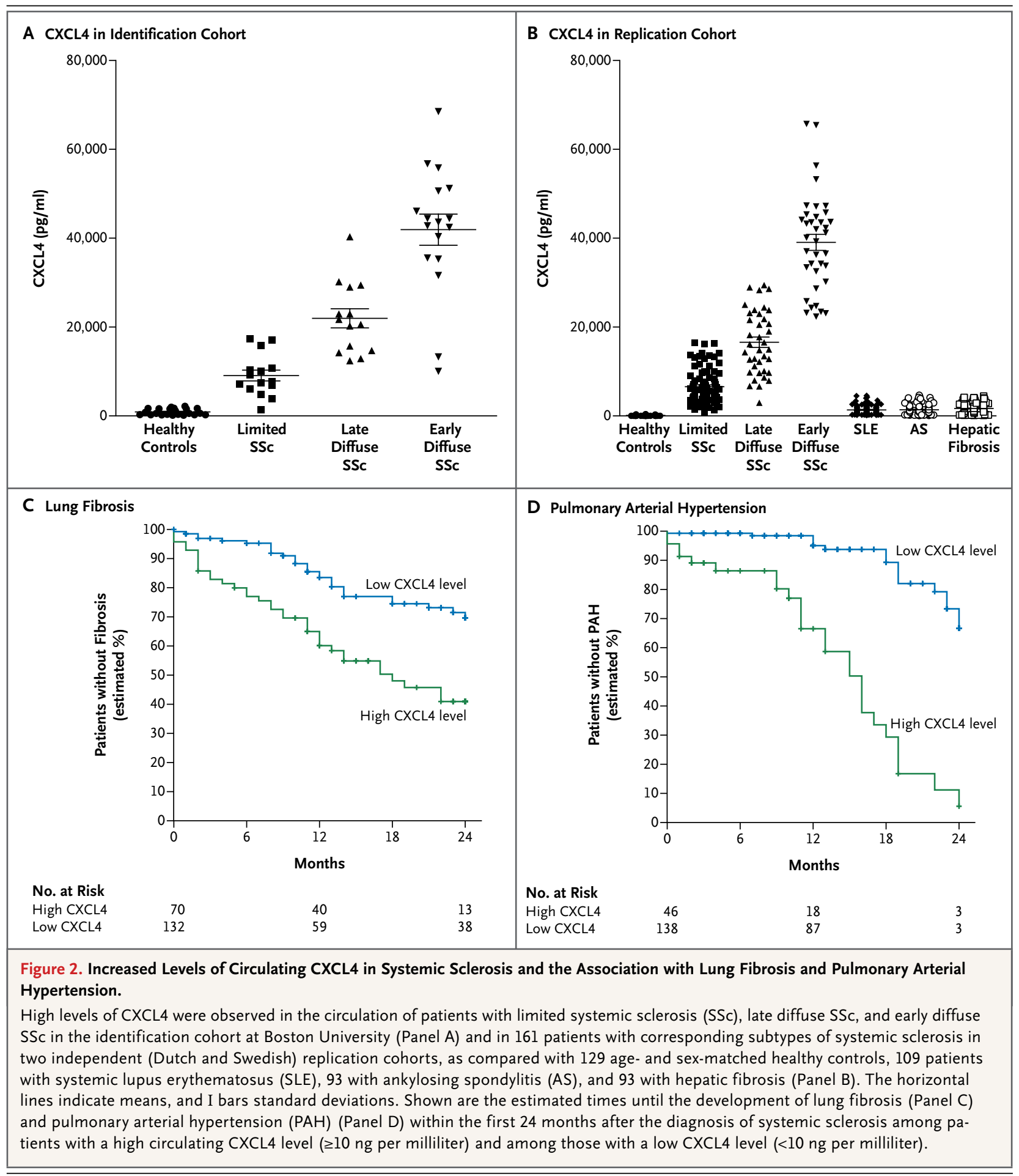


role in systemic sclerosis. On stimulation by ligands of toll-like receptors, plasmacytoid dendritic cells from patients with systemic sclerosis secreted more type I interferon than did those from controls, a difference that was fully reversed by the addition of anti-CXCL4 antibody or heparinase (Fig. 3C and 3D). In contrast, anti-CXCL12 antibody (SDF-1) did not have this effect (data not shown).
CXCL4 AND INFLAMMATORY CHANGES IN SKIN

To examine the possible role of CXCL4 in vivo, we used a recently described murine subcutaneouspump model. ${ }^{25}$ The subcutaneous administration of CXCL4 for 7 days resulted in a marked infiltration of inflammatory cells in the dermis and subdermis, as compared with that seen in mice infused with phosphate-buffered saline as a control (Fig. 4A and 4B). In addition, CXCL4 ad-

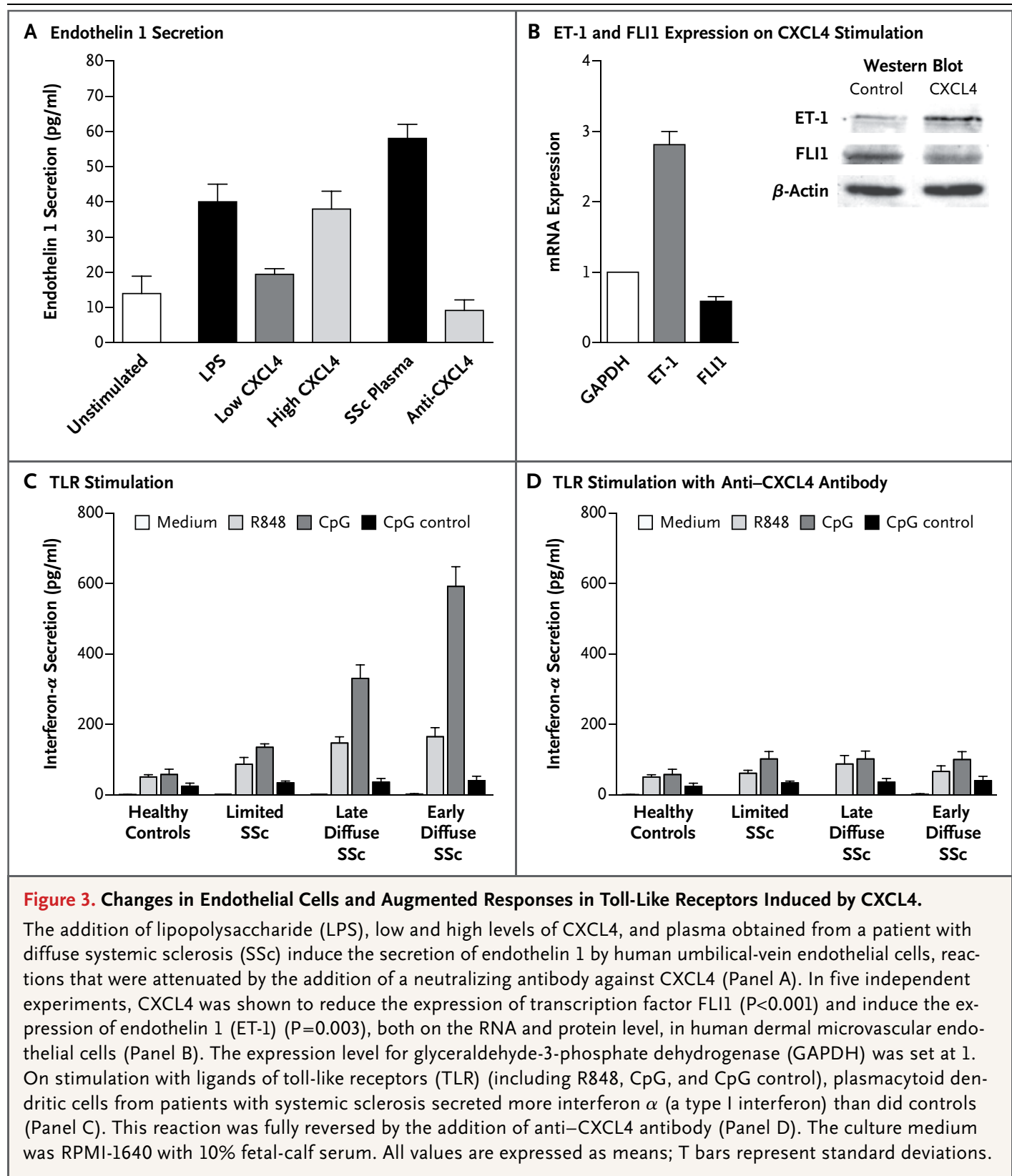




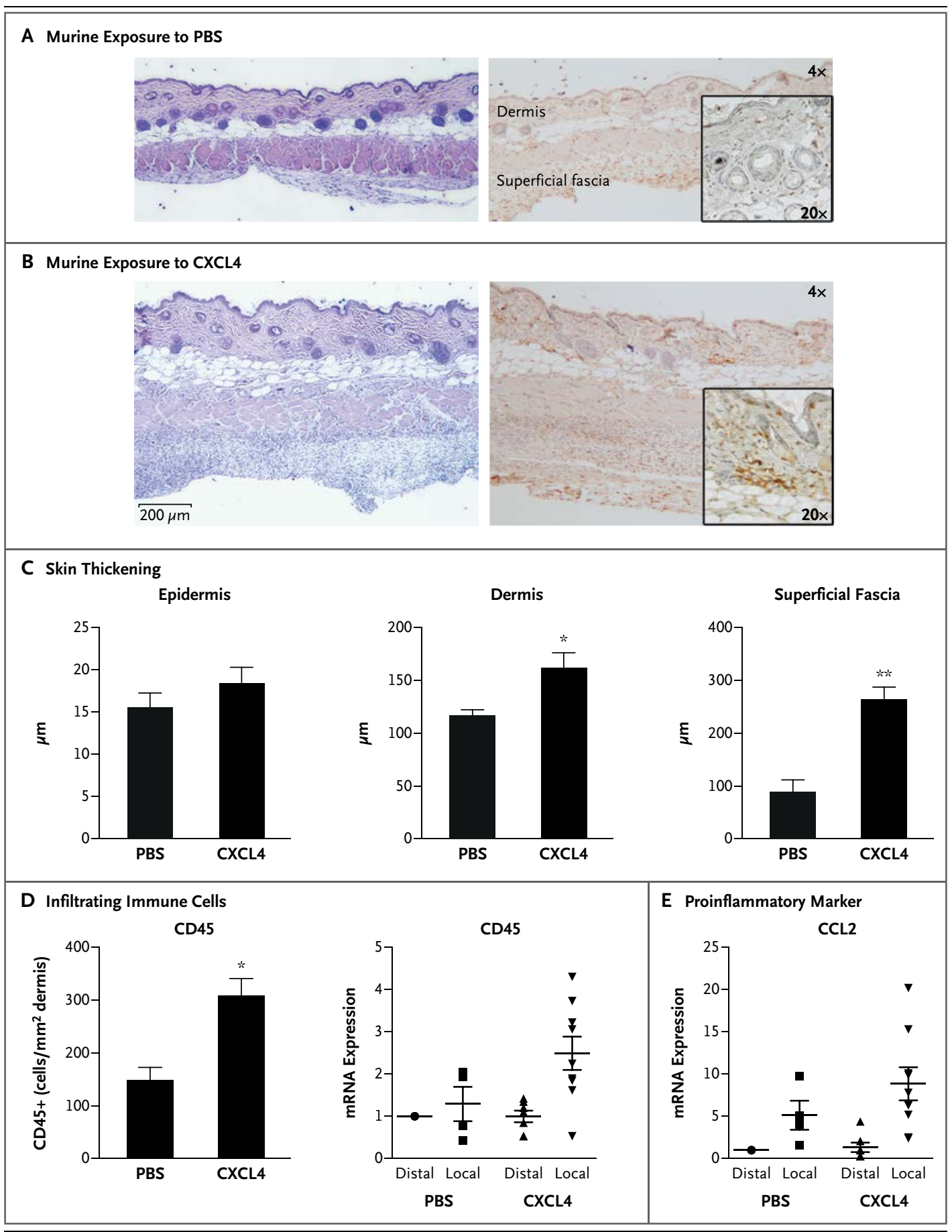

ministration resulted in a significant increase in inflammatory cells was confirmed by an inthe thickness of dermal and subdermal layers creased number of dermal CD45+ cells in the after 7 days (Fig. 4C). CXCL4-induced dermal CXCL4-treated skin, as well as increased expresthickening was also observed in a longer, 28-day sion of CD45 mRNA (Fig. 4D). Furthermore, we model of daily subcutaneous injection (Fig. S3D observed that CXCL4 induced the expression of in the Supplementary Appendix). The influx of the highly proinflammatory CCL2 in the two 
Figure 4 (facing page). Inflammatory Skin Changes Mimicking Those in Systemic Sclerosis Induced by CXCL4 In Vivo in Mice.

Panels $A$ and $B$ show the results of histologic analyses of skin from wild-type C57BL/6 mice that were treated with phosphate-buffered saline (PBS) as a control (Panel A) or with CXCL4 (Panel B) for 7 days with the use of a subcutaneous-pump model, shown at $4 \times$ and 20x magnification (hematoxylin and eosin, left; CD45 immunohistochemical staining, right). The murine sample that was treated with CXCL4 shows marked infiltration of inflammatory cells in the dermis and subdermis, as compared with the control sample. Panel $C$ shows quantification of the thickening of skin layers after CXCL4 treatment for 7 days with the use of the pump model, as compared with the PBS controls. Shown are mean values for three analyses in each group, with T bars indicating standard errors. Panel D shows the quantification of infiltrating immune cells after 7-day exposure to CXCL4 or PBS, in which CD45+ cells in the dermis were counted after immunohistochemical staining; the means of three analyses per group are shown (at left). In addition, the influx of inflammatory cells is confirmed by increased CD45 messenger RNA ( $m R N A$ ) expression in CXCL4-exposed skin isolated from the distal or proximal (local) area to the pump outlet, as measured on quantitative polymerasechain-reaction (PCR) assay (at right). In Panels $C$ and D, a single asterisk denotes $\mathrm{P}<0.05$ for the between-group comparison; double asterisks denote $\mathrm{P}<0.01$. Panel $\mathrm{E}$ shows the mRNA expression of proinflammatory marker CCL2 induced after 7-day exposure to CXCL4, as compared with PBS, also measured on quantitative PCR assay. In Panels $D$ and $E$, the mRNA analyses included 4 samples for PBS and 7 samples for CXCL4. The horizontal lines indicate means, and I bars standard errors.

models (Fig. 4E, and Fig. S3F in the Supplementary Appendix). During an investigation of the geneexpression profile in mice that were treated with CXCL4 for 7 days, we found increased mRNA expression of tumor necrosis factor $\alpha$, IFIT1, and MX2, the products of type I interferon-inducible genes; of the profibrotic marker PAI-1; and of the antiangiogenic factor thrombospondin 1 (Fig. S3A, $\mathrm{S} 3 \mathrm{~B}$, and S3C in the Supplementary Appendix).

\section{DISCUSSION}

In this study, we found that CXCL4 levels in patients with systemic sclerosis not only correlate strongly with both skin and pulmonary disease but also appear to predict progression in systemic sclerosis phenotypes. Collectively, the identification of CXCL4 as a marker for fibrosis and pul- monary arterial hypertension may be helpful in early diagnosis and risk assessment, an important factor in patients who require aggressive treatment. CXCL4 was one of the most highly and differentially expressed genes in a genomewide association study involving patients with systemic sclerosis who had pulmonary arterial hypertension and idiopathic pulmonary arterial hypertension, as compared with healthy controls. ${ }^{26}$

CXCL4 is a 70 -amino acid, lysine-rich, $7.8-\mathrm{kDa}$ protein that was first identified as a product of megakaryocytes and comprises 2 to $3 \%$ of the protein content of activated platelets. ${ }^{27}$ CXCL4 is generally well accepted as one of the most potent antiangiogenic chemokines, influencing angiogenesis through an integrin-dependent mechanism. ${ }^{28}$ The high levels of CXCL4 that were found in patients with systemic sclerosis are of great interest, since plasma obtained from these patients also showed antiangiogenic activity, and the disease is characterized by rarefaction of vessels despite the presence of multiple proangiogenic factors.

In addition to its antiangiogenic activity, CXCL4 inhibits the expression of the antifibrotic cytokine interferon- $\gamma$ (a type 1 helper $\mathrm{T}$ cell) and up-regulates profibrotic cytokines interleukin-4 and interleukin-13 (type 2 helper T cells). ${ }^{29}$ It also stimulates the proliferation of $\mathrm{T}$ regulatory cells with impaired suppressive function. ${ }^{30}$ Such data might indicate that the high levels of CXCL4 in patients with systemic sclerosis could be linked to features of immune dysfunction that have been observed in the disease. ${ }^{31}$ Accumulating evidence suggests a role for CXCL4 in other chronic fibroproliferative and inflammatory conditions. CXCL4 was shown to be an important mediator in atherosclerosis, both in vivo and in vitro, ${ }^{32}$ and increased CXCL4 levels have been associated with progressive liver fibrosis. ${ }^{33}$ Intriguingly, despite the fact that CXCL4 induced skin inflammation in vivo in mice, fibrosis was not observed. In this light, it is tempting to speculate that although CXCL4 may sensitize various cells to inflammatory stimuli, culminating in fibrosis, the presence of CXCL4 alone is not sufficient. This hypothesis is supported by our observation that increased levels of CXCL4 were found in patients with Raynaud's phenomenon, most of whom do not have progression to systemic sclerosis. 
Our data from cell culture and the murine model lead us to speculate that plasmacytoid dendritic cells, through the production of CXCL4, are pivotal in the onset and perpetuation of systemic sclerosis. In this respect, the downregulation of FLI1 is of particular interest, since selective endothelial-cell deletion of Fli-1 in mice leads to down-regulated expression of classic endothelial-cell markers, which are also seen to be down-regulated in the vasculature of patients with systemic sclerosis. The phenotype of Fli-1 knockout mice indicates a profound role for Fli-1 in vessel formation, maturation, and stabilization. ${ }^{34}$ In addition, CXCL4 induces the expression of thrombospondin 1 and attenuates the effects of vascular endothelial growth factor. These observations might explain the absence of neovascularization in systemic sclerosis, despite the presence of high levels of vascular endothelial growth factor. Thus, we speculate that CXCL4 may play a major role in vasculopathy associated with systemic sclerosis through altered FLI1 expression. The effect of FLI1 expression on fibroblasts may also be important, since FLI1 regulates elevated collagen synthesis, the hallmark of fibrosis. ${ }^{35}$

Several previous small studies have hinted at increased levels of CXCL4 and other inflammatory markers in the circulation of patients with systemic sclerosis. ${ }^{23,24,36-39}$ In those studies, the observed CXCL4 levels were attributed to platelet activation, a conclusion inconsistent with increased mRNA expression by peripheral-blood mono- nuclear cells, increased secretion of CXCL4 by plasmacytoid dendritic cells, and a lack of association between increased $\beta$-thromboglobulin levels and increased CXCL4 levels in patients with systemic sclerosis. Our data show that CXCL4 levels correlated highly with disease phenotype and disease progression in five large, independent, and clinically well-characterized patient cohorts, whereas levels of CCL2, CXCL10, CCL5, von Willebrand factor, and CCL18 did not show such correlation.

Taken together, our observations suggest that CXCL4 and plasmacytoid dendritic cells are central to the pathogenesis of systemic sclerosis. The levels of CXCL4 correlated well with the level of fibrosis and the occurrence and progression of pulmonary arterial hypertension, the two clinical hallmarks of this disorder. CXCL4 levels were also increased in several other fibrosing or inflammatory conditions, suggesting that CXCL4 may play a role in many pathologic conditions.

Supported by awards from the Dutch Arthritis Association (to Dr. Radstake), the Netherlands Organization for Scientific Research (to Drs. Radstake and Affandi), the Niels Stensen Foundation (to Dr. Radstake), the European Research Council (to Dr. Radstake), the European Community's FP6 (to Drs. Hesselstrand and Saxne), the National Institute of Arthritis and Musculoskeletal and Skin Diseases (grant no. IP50AR060780, to Dr. Lafyatis), and the German Research Foundation and the European Union (to Dr. Homey).

Disclosure forms provided by the authors are available with the full text of this article at NEJM.org.

We thank Dr. J.W.J. Jacobs for his review of an earlier version of the manuscript and assistance with the statistical analysis.

\section{APPENDIX}

The authors' full names and degrees are as follows: Lenny van Bon, M.D., Alsya J. Affandi, M.Sc., Jasper Broen, M.D., Ph.D., Romy B. Christmann, M.D., Ph.D., Renoud J. Marijnissen, Ph.D., Lukasz Stawski, M.Sc., Giuseppina A. Farina, M.D., Ph.D., Giuseppina Stifano, M.D., Allison L. Mathes, Ph.D., Marta Cossu, M.D., Michael York, M.D., Cindy Collins, M.A., Mark Wenink, M.D., Richard Huijbens, M.Sc., Roger Hesselstrand, M.D., Ph.D., Tore Saxne, M.D., Ph.D., Mike DiMarzio, M.Sc., Dirk Wuttge, M.D., Ph.D., Sandeep K. Agarwal, M.D., Ph.D., John D. Reveille, M.D., Ph.D., Shervin Assassi, M.D., Maureen Mayes, M.D., M.P.H., Yanhui Deng, Ph.D., Joost P.H. Drenth, M.D., Ph.D., Jacqueline de Graaf, M.D., Ph.D., Martin den Heijer, M.D., Ph.D., Cees G.M. Kallenberg, M.D., Ph.D., Marc Bijl, M.D., Ph.D., Arnoud Loof, M.Sc., Wim B. van den Berg, Ph.D., Leo A.B. Joosten, Ph.D., Vanessa Smith, M.D., Ph.D., Filip de Keyser, M.D., Ph.D., Rafaella Scorza, M.D., Ph.D., Claudio Lunardi, M.D., Ph.D., Piet L.C.M. van Riel, M.D., Ph.D., Madelon Vonk, M.D., Ph.D., Waander van Heerde, Ph.D., Stephan Meller, M.D., Bernhard Homey, M.D., Lorenzo Beretta, M.D., Ph.D., Mark Roest, Ph.D., Maria Trojanowska, Ph.D., Robert Lafyatis, M.D., and Timothy R.D.J. Radstake, M.D., Ph.D.

The authors' affiliations are as follows: the Arthritis Center (L. van Bon, A.J.A., J.B., R.B.C., L.S., G.A.F., G.S., A.L.M., M.Y., C.C., M.D., M.T., R.L., T.R.D.J.R.) and the Flow Cytometry Core Facility (Y.D.), Boston University School of Medicine, Boston; the Department of Rheumatology and Clinical Rheumatology and Laboratory of Translational Immunology (L. van Bon, A.J.A., J.B., R.J.M., M.C., M.W., R. Huijbens, W.B.B., T.R.D.J.R.) and the Research Laboratory of the Department of Clinical Chemistry and Hematology (M.R.), University Medical Center Utrecht, Utrecht, the Departments of Gastroenterology and Hepatology (J.P.H.D.), Internal Medicine (J.G.), and Endocrinology (M.H.) and the Central Laboratory of Hematology (A.L., W.H.) and Internal Medicine (L.A.B.J.), Radboud University Nijmegen Medical Center, and the Department of Rheumatology, University Medical Center Nijmegen (P.L.C.M.R., M.V.), Nijmegen, and the Department of Rheumatology and Clinical Immunology, University Medical Center Groningen, Groningen (C.G.M.K., M.B.) — all in the Netherlands; the Referral Center for Systemic Autoimmune Diseases, Fondazione IRCCS Ca' Granda Ospedale Maggiore Policlinico di Milano, Milan (M.C., R.S., L. Beretta), and the University of Verona, Verona (C.L.) - both in Italy; the Department of Rheumatology, Lund University Hospital, Lund, Sweden (R. Hesselstrand, T.S., D.W.); the Division of Rheumatology, Department of Internal Medicine, University of Texas Health Science Center, Houston (S.K.A., J.D.R., S.A., M.M.); Ghent University Hospital, Ghent, Belgium (V.S., F.K.); and the Department of Dermatology, Heinrich-Heine-University, Duesseldorf, Germany (S.M., B.H.). 
REFERENCES

1. Gabrielli A, Avvedimento EV, Krieg T. Scleroderma. N Engl J Med 2009;360:1989 2003.

2. LeRoy EC, Black C, Fleischmajer R, et al. Scleroderma (systemic sclerosis): classification, subsets and pathogenesis. J Rheumatol 1988;15:202-5.

3. Leroy EC. Connective tissue synthesis by scleroderma skin fibroblasts in cell culture. J Exp Med 1972;135:1351-62.

4. Lafyatis R, York M. Innate immunity and inflammation in systemic sclerosis Curr Opin Rheumatol 2009;21:617-22.

5. Gu YS, Kong J, Cheema GS, Keen CL, Wick G, Gershwin ME. The immunobiology of systemic sclerosis. Semin Arthritis Rheum 2008;38:132-60.

6. Gourh P, Agarwal SK, Divecha D, et al. Polymorphisms in TBX21 and STAT4 increase the risk of systemic sclerosis: evidence of possible gene-gene interaction and alterations in Th1/Th2 cytokines. Arthritis Rheum 2009;60:3794-806.

7. Rueda B, Broen J, Simeon C, et al. The STAT4 gene influences the genetic predisposition to systemic sclerosis phenotype. Hum Mol Genet 2009;18:2071-7.

8. Radstake TR, Gorlova O, Rueda B, et al Genome-wide association study of system ic sclerosis identifies CD247 as a new susceptibility locus. Nat Genet 2010;42:426-9. 9. Dieudé P, Guedj M, Wipff J, et al. Association between the IRF5 rs2004640 functional polymorphism and systemic sclerosis: a new perspective for pulmo nary fibrosis. Arthritis Rheum 2009;60 225-33.

10. York MR, Nagai T, Mangini AJ, Lemaire $\mathrm{R}$, van Seventer JM, Lafyatis R. A macro phage marker, Siglec-1, is increased on circulating monocytes in patients with systemic sclerosis and induced by type interferons and toll-like receptor agonists. Arthritis Rheum 2007;56:1010-20. [Erratum, Arthritis Rheum 2007;56:1675.] 11. Rönnblom L, Pascual V. The innate immune system in SLE: type I interferon and dendritic cells. Lupus 2008;17:394-9. 12. Gottenberg JE, Cagnard N, Lucches $\mathrm{C}$, et al. Activation of IFN pathways and plasmacytoid dendritic cell recruitment in target organs of primary Sjögren's syn drome. Proc Natl Acad Sci U S A 2006;103. 2770-5. [Erratum, Proc Natl Acad Sci U S A 2006;103:5242.]

13. van der Pouw Kraan TC, Wijbrandts CA, van Baarsen LG, et al. Rheumatoid arthritis subtypes identified by genomic profiling of peripheral blood cells: assignment of a type I interferon signature in a subpopulation of patients. Ann Rheum Dis 2007;66:1008-14.

14. Eloranta ML, Franck-Larsson K, Lövgren $\mathrm{T}$, et al. Type I interferon system activation and association with disease manifestations in systemic sclerosis. Ann Rheum Dis 2010;69:1396-402.

15. Kim D, Peck A, Santer D, et al. Induction of interferon-alpha by scleroderma sera containing autoantibodies to topoisomerase I: association of higher interferon-alpha activity with lung fibrosis. Arthritis Rheum 2008;58:2163-73.

16. Preliminary criteria for the classification of systemic sclerosis (scleroderma): subcommittee for scleroderma criteria of the American Rheumatism Association Diagnostic and Therapeutic Criteria Committee. Arthritis Rheum 1980;23:581-90.

17. Holewijn S, den Heijer M, Swinkels DW, Stalenhoef AF, de Graaf J. The metabolic syndrome and its traits as risk factors for subclinical atherosclerosis. J Clin Endocrinol Metab 2009;94:2893-9.

18. Tan EM, Cohen AS, Fries JF, et al. The 1982 revised criteria for the classification of systemic lupus erythematosus. Arthritis Rheum 1982;25:1271-7.

19. Hochberg MC. Updating the American College of Rheumatology revised criteria for the classification of systemic lupus erythematosus. Arthritis Rheum 1997;40:1725. 20. van der Heijde D, Bellamy N, Calin A, Dougados M, Khan MA, van der Linden S. Preliminary core sets for endpoints in ankylosing spondylitis. J Rheumatol 1997; 24:2225-9.

21. Distler O, Rinkes B, Hohenleutner U, et al. Expression of RANTES in biopsies of skin and upper gastrointestinal tract from patients with systemic sclerosis. Rheumatol Int 1999;19:39-46.

22. Kahaleh MB, Osborn I, LeRoy EC. Increased factor VIII/von Willebrand factor antigen and von Willebrand factor activity in scleroderma and in Raynaud's phenomenon. Ann Intern Med 1981;94:482-4. 23. Kodera M, Hasegawa M, Komura K, Yanaba K, Takehara K, Sato S. Serum pulmonary and activation-regulated chemokine/CCL18 levels in patients with systemic sclerosis: a sensitive indicator of active pulmonary fibrosis. Arthritis Rheum 2005;52: 2889-96.

24. Antonelli A, Ferri C, Fallahi P, et al. CXCL10 (alpha) and CCL2 (beta) chemokines in systemic sclerosis - a longitudinal study. Rheumatology (Oxford) 2008;47:45-9. 25. Farina G, York M, Collins C, Lafyatis R. dsRNA activation of endothelin-1 and markers of vascular activation in endothelial cells and fibroblasts. Ann Rheum Dis 2011;70:544-50

26. Rajkumar R, Konishi K, Richards TJ, et al. Genomewide RNA expression profiling in lung identifies distinct signatures in idiopathic pulmonary arterial hypertension and secondary pulmonary hypertension. Am J Physiol Heart Circ Physiol 2010;298: H1235-H1248.
27. Rollins BJ. Chemokines. Blood 1997; 90:909-28.

28. Aidoudi S, Bujakowska K, Kieffer N, Bikfalvi A. The CXC-chemokine CXCL4 interacts with integrins implicated in angiogenesis. PLoS One 2008;3(7):e2657. 29. Romagnani P, Maggi L, Mazzinghi B, et al. CXCR3-mediated opposite effects of CXCL10 and CXCL4 on TH1 or TH2 cytokine production. J Allergy Clin Immunol 2005;116:1372-9.

30. Liu CY, Battaglia M, Lee SH, Sun QH, Aster RH, Visentin GP. Platelet factor 4 differentially modulates CD4+CD25+ (regulatory) versus CD4+CD25- (nonregulatory) T cells. J Immunol 2005;174:2680-6.

31. Radstake TR, van Bon L, Broen J, et al. Increased frequency and compromised function of T regulatory cells in systemic sclerosis (SSc) is related to a diminished CD69 and TGFbeta expression. PLoS One 2009;4(6):e5981.

32. Pitsilos S, Hunt J, Mohler ER, et al. Platelet factor 4 localization in carotid atherosclerotic plaques: correlation with clinical parameters. Thromb Haemost 2003;90:1112-20.

33. Zaldivar MM, Pauels K, von Hundelshausen $\mathrm{P}$, et al. CXC chemokine ligand 4 (Cxcl4) is a platelet-derived mediator of experimental liver fibrosis. Hepatology 2009;51:1345-53.

34. Asano Y, Stawski L, Hant F, et al. Endothelial Fli1 deficiency impairs vascular homeostasis: a role in scleroderma vasculopathy. Am J Pathol 2010;176:1983-98.

35. Kubo M, Czuwara-Ladykowska J, Moussa $\mathrm{O}$, et al. Persistent down-regulation of Fli1, a suppressor of collagen transcription, in fibrotic scleroderma skin. Am J Pathol 2003;163:571-81.

36. Farina G, Lafyatis D, Lemaire R, Lafyatis R. A four-gene biomarker predicts skin disease in patients with diffuse cutaneous systemic sclerosis. Arthritis Rheum 2010; 62:580-8.

37. Kowal-Bielecka O, Kowal K, Lewszuk A, Bodzenta-Lukaszyk A, Walecki J, Sierakowski S. Beta thromboglobulin and platelet factor 4 in bronchoalveolar lavage fluid of patients with systemic sclerosis. Ann Rheum Dis 2005;64:484-6.

38. Scheja A, Akesson A, Geborek P, et al. Von Willebrand factor propeptide as a marker of disease activity in systemic sclerosis (scleroderma). Arthritis Res 2001; 3:178-82.

39. Hasegawa M, Fujimoto M, Matsushita T, Hamaguchi Y, Takehara K, Sato S. Serum chemokine and cytokine levels as indicators of disease activity in patients with systemic sclerosis. Clin Rheumato 2011;30:231-7.

Copyright (c) 2013 Massachusetts Medical Society. 